\title{
Desapariciones forzadas: una violación al derecho internacional humanitario y derecho internacional de derechos humanos
}

Ilda Lilian Cartagena Santos ${ }^{1}$

\section{RESUMEN}

Se desarrolla un análisis sobre el derecho internacional de los derechos humanos y el derecho internacional humanitario, vinculando ambos al reflexionar sobre el problema de las desapariciones forzadas, ya que éste es un delito complejo, múltiple y acumulativo, que supone la violación de un conjunto diverso de derechos humanos y que cometido en determinadas circunstancias, conflictos armados internacionales como en conflictos internos, constituye también un crimen de lesa humanidad.

Palabras clave: Desapariciones forzadas, Personas, Conflictos armados, Violencia interna, Privación arbitraria de la libertad, Violación de derechos humanos, Derecho Internacional Humanitario, Derecho Internacional de Derechos Humanos.

\section{ABSTRACT}

An analysis on international law regarding human rights and international humanitarian law is been developed, joining both and thinking on the problem on forced disappearances because this is a multiple, accumulative and complex crime that implies a diverse violation of human rights and committed under certain circumstances, international armed conflicts, as in internal conflicts also constitute crimes againsthumanity

Key word: Forced disappearances, People, Armed conflicts, Internal violence, Arbitrary privation of liberty, Violation of human rights, International humanitarian law, International human rights law.

${ }^{1}$ Universidad Nacional Autónoma de Honduras. Maestría en Derechos Humanos y Desarrollo. 


\section{INTRODUCCIÓN}

Este trabajo tiene como objetivo destacar la importancia del Derecho Internacional de los Derechos Humanos y del Derecho Internacional Humanitario, abordando como problema jurídico - social las desapariciones forzadas, que constituyen una violación de ambos derechos. Para ello es importante tener en cuenta la distinción entre el Derecho Internacional de los Derechos Humanos y el Derecho Internacional Humanitario.

Este se realizará un breve análisis sobre sus analogías y diferencias, vinculando ambos derechos al tema central de este ensayo, ya que las desapariciones forzadas son una violación del Derecho Internacional Humanitario y de los derechos humanos, tanto en los conflictos armados internacionales como en los conflictos sin carácter internacional. Violan una serie de normas consuetudinarias fundamentales, como la prohibición de la privación arbitraria de libertad, la prohibición de la tortura y otros tratos inhumanos y crueles, así como la prohibición de las ejecuciones. Dejar a las familias sin noticias de la situación y del paradero de sus seres queridos no sólo las pone en una insoportable situación de incertidumbre, sino que es también una negación del derecho a la vida en familia y del derecho de las familias a conocer la suerte y el paradero de sus seres queridos.

La prohibición de las desapariciones forzadas, como todas las normas de derecho humanitario, no da cabida a las excepciones. Ni la guerra, ni un estado de excepción, ni razones imperativas de seguridad nacional, pueden justificar las desapariciones forzadas. Del mismo modo, ningún Estado, grupo o individuo está por encima de la ley, y nadie puede quedar fuera del derecho.

Para delimitar este campo de estudio que merece la atención, se desarrolla una parte teórica y doctrinal evidenciando el problema de estudio en el marco internacional de derechos humanos y de Derecho Internacional Humanitario, finalizando con un aporte en el caso de Honduras.

\section{GENERALIDADES, ANALOGÍAS Y DIFERENCIAS ENTRE EL DERECHO INTERNACIONAL DE LOS DERECHOS HUMANOS Y EL DERECHO INTERNACIONAL HUMANITARIO}

\section{Generalidades}

En 1948, se creó la base jurídica del siglo XX en materia de derechos humanos: la "Declaración Universal de Derechos Humanos", como ideal común por el que todos 
los pueblos y naciones deben esforzarse. Esta "Declaración", junto con el "Pacto Internacional sobre Derechos Civiles y Políticos", el "Pacto Internacional de Derechos Económicos, Sociales y Culturales" y sus respectivos protocolos opcionales, conforman la "Carta Internacional de los Derechos Humanos". Estos pactos fueron establecidos el 16 de diciembre de 1966 e imparten obligatoriedad jurídica a los derechos proclamados por la Declaración.

El Derecho Internacional Humanitario y el Derecho Internacional de los Derechos Humanos son dos ordenamientos jurídicos diferentes pero complementarios. La finalidad de ambos es proteger a las personas contra los actos arbitrarios y los abusos. Los derechos humanos son inherentes al ser humano y protegen a las personas en todas las circunstancias, en tiempo de guerra y de paz. El Derecho Internacional Humanitario sólo se aplica en situaciones de conflicto armado. Por lo tanto, en tiempo de conflicto armado, el Derecho Internacional de los Derechos Humanos y el Derecho Internacional Humanitario se aplican de manera complementaria.

Si el derecho humanitario tiene por objeto proteger a las víctimas procurando limitar los sufrimientos provocados por la guerra, los derechos humanos protegen a la persona humana y favorecen su completo desarrollo.

Es decir, que el derecho humanitario se ha elaborado para mitigar los efectos de los conflictos armados. Limita los medios y métodos que se pueden utilizar en las operaciones militares y obliga a los combatientes a no atacar a la población civil, nia las personas que ya no participan en las hostilidades, como los soldados que han resultado heridos 0 se han entregado. La principal finalidad de los derechos humanos es impedir la arbitrariedad, limitando el dominio del Estado sobre los individuos; no es su objeto regular la conducción de las operaciones militares.

Para garantizar su respeto, el derecho humanitario establece mecanismos que instituyen un tipo de control continuo de su aplicación y hace resaltar la cooperación entre las partes en conflicto y un intermediario neutral, con miras a impedir las eventuales violaciones. Es decir, el modo de acción del Comité Internacional de la Cruz Roja (CICR), cuyo cometido es, en particular, velar por el respeto del derecho humanitario.

Por lo que atañe a los derechos humanos, los mecanismos de control son muy variados. En muchos casos, las instituciones previstas se encargan de determinar si un Estado ha respetado o no el derecho. Así, la Corte Europea de Derechos Humanos está habilitada, especialmente, tras un procedimiento incoado por 
iniciativa de un individuo, a declarar que la Convención Europea de Derechos Humanos ha sido violada por una autoridad nacional. Ésta se verá entonces obligada a tomar las oportunas medidas para que en tal situación se respeten, a nivel interno, las exigencias de la Convención. Los mecanismos de aplicación de los derechos humanos están esencialmente orientados hacia las acciones de reparación de los perjuicios sufridos.

En conflictos de todo el mundo, los gobiernos y los grupos armados, atacan a civiles sistemáticamente y cometen crímenes de guerra y terribles abusos contra los derechos humanos. Sin embargo, incluso en la guerra, hay normas que todos los bandos están legalmente obligados a cumplir.

La inmensa mayoría de los conflictos actuales son internos. Muchos han persistido durante décadas, pese a los grandes esfuerzos internacionales por ponerles solución. Estos conflictos estallan a menudo por cuestiones de identidad, etnia, religión y competencia por los recursos, especialmente el petróleo y la riqueza mineral.

\section{Analogías y Diferencias}

La finalidad tanto del Derecho Internacional Humanitario (DIH) como del Derecho Internacional de los Derechos Humanos (DIDH) es proteger la vida, la salud y la dignidad de las personas, pero desde puntos de vista diferentes. Así pues, no ha de sorprender que, a pesar de una formulación muy diferente, la esencia de algunas normas sea similar, o incluso idéntica. Por ejemplo, los dos derechos protegen la vida humana, prohíben la tortura u otros tratos crueles, estipulan los derechos fundamentales de las personas contra las cuales se abre un proceso penal, prohíben la discriminación, disponen acerca de la protección de las mujeres y los niños, reglamentan aspectos del derecho a los alimentos y a la salud. Sin embargo, el DIH contiene disposiciones sobre muchas cuestiones que están por fuera del ámbito del DIDH, como la conducción de las hostilidades, los estatutos de combatiente y de prisionero de guerra y la protección del emblema de la Cruz Roja y de la Media Luna Roja. Del mismo modo, el DIDH dispone acerca de aspectos de la vida en tiempo de paz que no están reglamentados por el DIH, como la libertad de prensa, el derecho a reunirse, a votar y a declararse en huelga.

El Derecho Internacional Humanitario. Es un conjunto de normas internacionales, convencionales o consuetudinarias, destinadas a resolver los problemas causados directamente por conflictos armados internacionales o no internacionales. Protege a las personas y los bienes afectados, o que pueden 
resultar afectados, por un conflicto armado, y limita el derecho de las partes en conflicto a elegir los métodos y medios de hacer la guerra. Los principales tratados de DIH aplicables en caso de conflicto armado internacional, son los cuatro Convenios de Ginebra de 1949 y su Protocolo adicional I de 1977. Las principales disposiciones convencionales aplicables en caso de conflicto armado no internacional, son el artículo 3 común a los Convenios de Ginebra y las disposiciones del Protocolo adicional II.

El Derecho Internacional de los Derechos Humanos. Es un conjunto de normas internacionales, convencionales o consuetudinarias, en que se estipula el comportamiento y los beneficios que las personas o grupos de personas pueden esperar o exigir de los Gobiernos. Los derechos humanos son derechos inherentes a todas las personas por su condición de seres humanos.

Las principales fuentes convencionales del DIDH son los Pactos Internacionales de Derechos Civiles y Políticos (1966) y de Derechos Económicos, Sociales y Culturales (1966), las Convenciones relativas al Genocidio (1948), la Discriminación Racial (1965), la Discriminación contra la Mujer (1979), la Tortura (1984) y los Derechos del Niño (1989). Los principales instrumentos regionales son el Convenio Europeo para la Protección de los Derechos Humanos y de las Libertades Fundamentales (1950), la Declaración Americana de Derechos y Deberes del Hombre (1948), la Convención Americana sobre Derechos Humanos (1969) y la CartaAfricana sobre Derechos Humanos y de los Pueblos (1981).

A pesar de que el DIH y el DIDH han tenido un desarrollo independiente desde el punto de vista histórico, en tratados recientes se han incluido disposiciones de ambos derechos; por ejemplo, en la Convención sobre los Derechos del Niño, en su Protocolo Facultativo relativo a la participación de los niños en los conflictos armados y en el Estatuto de Roma de la Corte Penal Internacional.

¿Cuándo se aplican estos derechos? El DIH es aplicable en tiempo de conflicto armado, internacional o no internacional. Las guerras en que intervienen dos 0 varios Estados y las guerras de liberación con conflictos internacionales, en que haya habido una declaración de guerra o no, y aunque una de las partes no haya reconocido el estado de guerra.

Los conflictos armados no internacionales son aquellos en que fuerzas gubernamentales combaten contra insurgentes armados o en que grupos rebeldes combaten entre ellos. 
Dado que el DIH impone normas a una situación excepcional -un conflicto armadono están permitidas las excepciones a la aplicación de sus disposiciones. El DIDH se aplica en todo tiempo: en tiempo de paz y en tiempo de conflicto armado. Sin embargo, de conformidad con algunos tratados de DIDH, los Gobiernos pueden derogar algunas normas en situaciones de emergencia pública que pongan en peligro la vida de la nación, a condición de que las derogaciones sean proporcionadas a la crisis y su aplicación no sea indiscriminada o infrinja alguna otra norma del derecho internacional, incluido el DIH.

Hay normas que no permiten derogación alguna, como las relativas al derecho a la vida, y las que prohíben la tortura, tratos o penas crueles, inhumanos 0 degradantes, la esclavitud y la servidumbre y la retroactividad de las leyes penales.

¿Quién debe aplicar las disposiciones de estos derechos? El DIH debe ser aplicado por todas las partes en un conflicto armado: en los conflictos internacionales, debe ser acatado por los Estados implicados y, en los conflictos internos, por los grupos que combatan contra el Estado o que combatan entre ellos.

En el DIDH se imponen obligaciones a los Gobiernos en sus relaciones con los individuos. Muchos opinan que los agentes no estatales especialmente los que ejercen funciones de índole gubernamental también tendrían que respetar las normas de derechos humanos.

El DIH impone también obligaciones a las personas naturales y establece que pueden ser consideradas penalmente responsables por "infracciones graves" de los Convenios de Ginebra y del Protocolo I, y por otras violaciones graves de las normas y costumbres de la guerra (crímenes de guerra). Se estipula la jurisdicción universal con respecto a las personas sospechosas de haber cometido dichos actos. Con la aprobación del Estatuto de la Corte Penal Internacional, las personas también deben responder por crímenes de guerra cometidos en conflictos armados no internacionales.

De conformidad con los tratados de DIDH, las personas naturales no tienen deberes específicos, pero sí pueden ser declaradas responsables penalmente por violaciones que puedan constituir crímenes internacionales, como el genocidio, los crímenes de lesa humanidad y la tortura, los cuales están sujetos también a la jurisdicción universal. Los Tribunales Penales Internacionales para ex Yugoslavia y Ruanda, así como la Corte Penal Internacional tienen jurisdicción con respecto a violaciones tanto del DIH como del DIDH. 
¿Quién se beneficia de la protección del DIH y DIDH? EI DIH protege a las personas que no participan, o que han dejado de participar, en las hostilidades. Los Convenios de Ginebra, aplicables en caso de conflicto armado internacional, protegen a los heridos y los enfermos de las fuerzas armadas en campaña (Convenio I), a los heridos, los enfermos y los náufragos de las fuerzas armadas en el mar (Convenio II), a los prisioneros de guerra (Convenio III) y a las personas civiles (Convenio IV). Los desplazados internos, las mujeres, los niños, los refugiados, los apátridas, los periodistas, entre otros, forman parte de la categoría de persona civil (Convenio IV y Protocolo I). Del mismo modo, las normas aplicables en caso de conflicto armado no internacional (Protocolo Il y artículo 3 común a los Convenios de Ginebra) se refieren al trato debido a las personas que no participan, o que han dejado de participar, en las hostilidades.

Las normas del DIH relativas a la conducción de las hostilidades protegen tambiéna las personas civiles. Por ejemplo, las partes en conflicto deben, en todo tiempo, distinguir entre combatientes y no combatientes y entre objetivos militares y no militares. El DIDH, cuya aplicación está prevista, principalmente, para el tiempo de paz, protege a todas las personas.

\section{DESAPARICIÓN FORZADA: UNA VIOLACIÓN AL DERECHO INTERNACIONAL HUMANITARIO YDERECHO INTERNACIONAL DE DERECHOS HUMANOS.}

El problema de las personas desaparecidas y la asistencia a sus familiares es abordado tanto por el Derecho Internacional Humanitario como por el Derecho Internacional de los Derechos Humanos desde sus respectivos ámbitos de aplicación, siendo marcos jurídicos distintos.

\section{Conceptualización y Marco Jurídico de las Desapariciones Forzadas.}

¿Qué se entiende por desaparecidos? Personas desaparecidas son aquellas cuya suerte se desconoce a raíz de situaciones de conflicto armado o de violencia interna.

Las desapariciones son un problema de alcance mundial, que padecen muchos países y poblaciones. Los familiares de los desaparecidos desconocen el paradero de éstos o la suerte que han corrido, lo que puede suceder en las siguientes situaciones:

Las familias de miembros de las fuerzas armadas o de grupos armados, desconocen a menudo el paradero de éstos porque no disponen de medios para 
mantenerse en contacto con ellos. A veces se da por desaparecidos en acción, a miembros de las fuerzas armadas o de grupos armados porque no llevaban ningún medio de identificación.

Las personas capturadas, detenidas o secuestradas pueden ser asesinadas. Las personas privadas de libertad pueden morir en cautiverio, desaparecer 0 estar incomunicadas o recluidas en un lugar secreto. En muchos casos, no se permite a sus familiares visitarlos ni mantener correspondencia con ellas.

Los asesinatos en masa siguen siendo, desafortunadamente, la causa de que no se tenga noticia de muchas personas. Cuando esto ocurre, no se entierran los cadáveres o se entierran a toda prisa, y a veces se destruyen.

\section{Desaparición Forzada}

La Convención Interamericana sobre Desaparición Forzada de Personas, adoptada en Belém do Pará, Brasil el 9 de junio de 1994, en el vigésimo cuarto período ordinario de sesiones de la Asamblea General, define en su artículo II, la desaparición forzada como "la privación de la libertad a una o más personas, cualquiera que fuere su forma, cometida por agentes del Estado o por personas 0 grupos de personas que actúen con la autorización, el apoyo o la aquiescencia del Estado, seguida de la falta de información o de la negativa a reconocer dicha privación de libertad o de informar sobre el paradero de la persona, con lo cual se impide el ejercicio de los recursos legales y de las garantías procesales pertinentes".

En tal sentido la desaparición forzada es un delito complejo, múltiple y acumulativo ya que atenta contra un conjunto diverso de derechos fundamentales, como: Derecho a la vida; Derecho a la libertad y a la seguridad personal; Derecho a trato humano y respeto a la dignidad; Derecho al reconocimiento de la personalidad jurídica; Derecho a la identidad y a la vida familiar, especialmente en el caso de los niños; Derecho a reparación, incluso mediante la indemnización; Derecho a la libertad de opinión, expresión e información; Derechos laborales y políticos.

Este conjunto de derechos vulnerados fueron la conclusión de las primeras sentencias formuladas por organismos internacionales en los años ochenta a partir de los derechos reconocidos, entre otras legislaciones, por el Pacto Internacional de Derechos Civiles y Políticos de 1966 o la Convención Americana sobre Derechos Humanos de 1969 y que sirvieron para desarrollar la jurisprudencia internacional relativa a este crimen.

Una de las características de la desaparición forzada es la indefensión jurídica 
absoluta de la víctima que queda desprotegida de los recursos elementales de habeas corpus o de amparo como resultado de la actuación de manera deliberadamente secreta de quienes cometen el crimen. Esta circunstancia, sin embargo, permite que su defensa pueda ser ejercida por cualquier persona cercana, familiar o amigo, o incluso una organización no gubernamental, generalmente un organismo defensor de derechos humanos.

\section{Marco jurídico aplicable}

En el plano jurídico internacional es innegable el reconocimiento de los derechos individuales a partir de 1948, cuando fue proclamada la Declaración Universal de los Derechos Humanos por la Organización de las Naciones Unidas.

Tomando como base dicha declaración, la desaparición forzada de personas constituye un delito permanente que viola un conjunto de normas destinadas a garantizar la vigencia de los derechos humanos, adoptadas en la forma de convenciones y pactos internacionales que constituyen obligaciones para los Estados signatarios.

La desaparición forzada viola los artículos 3, 5, 8, 9 y 10 de la Declaración Universal en los que se consagran los derechos a la vida, la libertad y la seguridad personal.

En este sentido, es posible afirmar sin lugar a dudas que los Estados responsables de este delito violan los artículos 1, 2, 12, 13, y 14, de la Convención Contra la Tortura y Otros Tratos o Penas Crueles, Inhumanos y Degradantes.

Por otra parte, son violados los artículos 9 y 10 del Pacto Internacional de Derechos Civiles y Políticos, en los que se establecen los derechos a la libertad y a la seguridad y a no sufrir detenciones arbitrarias ni prisión injusta, así como el derecho a recibir un trato acorde con la dignidad humana en caso de detención.

El Código de Conducta Para los Funcionarios Encargados de Hacer Cumplir la Ley, producto de una declaración de la Asamblea de la Organización de Naciones Unidas, es violado en las normas 5 y 6 .

En caso de guerra, la desaparición forzada de prisioneros vulnera además derechos expresamente establecidos en los cuatro Convenios de Ginebra del 12 de agosto de 1949 y sus dos Protocolos Adicionales: derecho a recibir un trato humano; derecho a recibir protección frente a actos de violencia; derecho a no ser sometido a tortura física o mental o a otras formas de coacción; derecho del prisionero a que sus 
familiares y la Agencia Central de Prisioneros de Guerra del Comité Internacional de la Cruz Roja, sean informados de su captura o traslado a otro campo (artículo 70); derecho a mantener correspondencia (artículo 71); derecho de ser liberados una vez finalizadas las hostilidades (artículo 118).

La Convención Interamericana sobre Desaparición Forzada de Personas fue aprobada el 9 de junio de 1994 en Belém do Pará, Brasil, mediante la resolución 1256 de laAsamblea General de la Organización de Estados Americanos.

\section{Derecho Internacional Humanitario y las desapariciones de personas a raíz de un conflicto armado}

La consideración principal de las normas específicas de Derecho Internacional Humanitario, en particular los cuatro Convenios de Ginebra de 1949 y sus dos Protocolos adicionales, relativa a las personas desaparecidas y las personas fallecidas, es "el derecho que asiste a las familias de conocer la suerte de sus miembros". Cada parte en un conflicto tiene la obligación de buscar a las personas cuya desaparición haya señalado la parte adversa.

Las personas desaparecidas pueden estar vivas o muertas. Si están con vida, pueden estar detenidas por el enemigo o en libertad, pero separadas de sus familiares. En ambos casos, tienen derecho a recibir la protección que se dispone en el Derecho Internacional Humanitario para la categoría a la que pertenezcan (personas civiles, prisioneros de guerra, heridos y enfermos, etc.). Además, en el Derecho Internacional Humanitario hay disposiciones por las que no se considera desaparecida a la mayoría de esas personas.

Si se considera desaparecida a una persona a raíz de la interrupción del servicio postal y de los movimientos de población que suelen ocurrir en tiempo de conflicto armado, el contacto entre familiares debería ser rápidamente restablecido, siempre que las partes en el conflicto cumplan con su obligación de facilitar el intercambio de noticias entre familiares y la reunión de éstos. Si las personas están desaparecidas porque han sido detenidas $u$ hospitalizadas por el enemigo, en el Derecho Internacional Humanitario se estipula que sus familiares y las autoridades deben ser rápidamente informadas a través de tres canales: notificación de la hospitalización, captura 0 arresto; transmisión de tarjetas de captura o de internamiento; y por el derecho que les asiste, intercambio de correspondencia con su familia. Las autoridades detenedoras también tienen la obligación de responder a las solicitudes de información acerca de personas protegidas.

Si la persona desaparecida está muerta, es más difícil informar a la familia. No existe 
obligación alguna de que cada parte identifique los cadáveres encontrados. Debe tratar de recabar información que contribuya a la identificación de la persona fallecida; esto incluye el hecho de ponerse de acuerdo para designar grupos que se ocupen de buscar a los muertos. En el Derecho Internacional Humanitario vigente no se estipula que las familias tengan derecho a recibir los restos mortales de sus miembros fallecidos, sea para proceder a su entierro o para identificarlos con certeza.

En algunos países, ha surgido otro problema en los últimos años, donde las familias no quedan satisfechas con la información que tienen derecho a recibir de conformidad con el Derecho Internacional Humanitario. No consideran fidedignos los certificados de defunción expedidos por el (ex) enemigo y quieren que les devuelvan los restos mortales de sus seres queridos.

Sin embargo, es loable destacar la misión que cumple el Comité Internacional de la Cruz Roja (CICR), quien actúa en las situaciones de conflicto armado o de violencia interna para proteger la vida y la dignidad de las personas, así como prevenir las desapariciones y determinar el paradero de los desaparecidos, en cumplimiento del cometido que la comunidad internacional le ha confiado.

EI CICR se esfuerza por poner fin a las desapariciones. Las visitas que hace con regularidad a los centros de detención son uno de los principales medios del CICR para lograr esa finalidad.

Por lo anterior y resumiendo, podemos decir que mientras que a un particular no combatiente en tanto responsable por la violación de derechos fundamentales de otras personas, le son aplicables las normas del código penal, a los combatientes, sean del Estado o de grupos al margen de la ley, le son aplicables además de las normas del código penal, las del Derecho Internacional Humanitario, por sus posibles infracciones. En cambio, los derechos humanos, en sentido estricto, son de responsabilidad exclusiva de los agentes del Estado, usen o no armas.

\section{Países con desapariciones forzadas a raíz de recientes conflictos armados}

Afganistán: desde 1979: Una centena de soldados rusos ha desaparecido. Millares de familias afganas y de otras nacionalidades no conocen el paradero de sus familiares desaparecidos.

Angola: desde 1975: Decenas de millares de familias están separadas de sus familiares desaparecidos de los cuales no tienen noticias. 
Armenia / Azerbaiyán / Nagorno Karabaj: 1992-1994: Millares de familias no conocen el paradero de sus familiares desaparecidos.

Bosnia y Herzegovina / Croacia/la ex República Yugoslava de Macedonia / Yugoslavia: 1992-2000: Varias decenas de Millares de familias no conocen el paradero de sus familiares desaparecidos.

Colombia: desde 1992: Millares de familias no conocen el paradero de sus familiares desaparecidos.

Eritrea / Etiopía: 1998-2000: Decenas de millares de familias no conocen el paradero de sus familiares desaparecidos.

Federación de Rusia / Chechenia: desde 1994: Millares de familias no conocen el paradero de sus familiares desaparecidos.

Guerra del Golfo: 1990-1991: Centenas de familias no conocen el paradero de sus familiares desaparecidos.

Irán (República Islámica del) / Irak: 1980-1988: Decenas de Millares de familias no conocen el paradero de sus familiares desaparecidos.

México: 1960 - 1980: Docenas de familias no conocen el paradero de sus familiares desaparecidos.

Perú: 1980-2000: Más de 6000 familias no conocen el paradero de sus familiares desaparecidos.

República Democrática del Congo: desde 1960: Centenas de Millares de familias no conocen el paradero de sus familiares desaparecidos.

Rwanda: desde 1991: Centenas de Millares de personas fueron asesinadas. Los familiares supervivientes nunca fueron oficialmente informados de su muerte.

Sáhara occidental: 1975-1991: Centenas de familias no conocen el paradero de sus familiares desaparecidos.

Sri Lanka: desde 1983: Millares de familias no conocen el paradero de sus familiares desaparecidos. 
Timor oriental: 1975-1999: Millares de familias no conocen el paradero de sus familiares desaparecidos.

\section{DESAPARICIONES FORZADAS EN HONDURAS}

Honduras también padece de una historia de violencia, aunque el país evadió el conflicto armado interno durante la Guerra Fría; sin embargo el gobierno utilizó medidas extremas, incluidas las ejecuciones extrajudiciales y las desapariciones forzadas, para controlar y eliminar toda oposición política. Además la violencia en el país aumentó cuando los Estados Unidos comenzó a utilizar a Honduras como base para sus operaciones contra la guerrilla salvadoreña y en apoyo a los "contras" nicaragüenses.

La actividad de los escuadrones de la muerte comenzó en la década de 1980, coincidiendo con las actividades en Honduras de la Agencia Central de Inteligencia de los Estados Unidos, como parte de sus esfuerzos por derrocar al gobierno sandinista en Nicaragua. En ese entonces por ejemplo, la CIA (por sus siglas en inglés), se asoció con el establecimiento y entrenamiento de un escuadrón de la muerte clandestino conocido como "Batallón 3-16" para luchar contra los sandinistas. El nombre de Batallón 3-16 se convirtió posteriormente en Honduras en sinónimo de tortura, asesinato y desapariciones.

En 1982, 69 familias hondureñas eran víctima de la desaparición forzada, y a finales de ese año, el 30 de noviembre, 12 familias se aglutinan y conforman el Comité de Familiares de Detenidos Desaparecidos en Honduras que nace con objetivos claros y definidos de recuperar con vida a sus parientes desaparecidos por el Estado. Entre 1980 y 1989 ciento ochenta y cuatro personas desaparecieron sin que las autoridades investigaran y sancionaran a los responsables.

En 1988 y 1989, la Corte Interamericana de los Derechos Humanos encontró al Estado de Honduras responsable de la desaparición de Manfredo Velásquez y Saúl Godínez Crúz y lo condenó a indemnizar a los familiares de las víctimas y castigar a los responsables. En el año 2003 el Estado de Honduras volvió a ser condenado en la misma Corte por la desaparición seguida de muerte de Juan Humberto Sánchez, en 1992.

El derecho penal hondureño no establece como delito autónomo la conducta de la desaparición forzada de personas, tal y como lo exigen la Declaración y la Convención Interamericana sobre Desaparición Forzada de Personas, de la que Honduras es Parte. Sin embargo el gobierno hondureño realiza algunos esfuerzos 
encomiables de búsqueda de personas desaparecidas tal y como lo deja establecido, la Asamblea General de las Naciones Unidas en el Informe del Grupo de Trabajo sobre Desapariciones Forzadas o Involuntarias, Misión a Honduras del mes de febrero de 2007.

\section{CONCLUSIONES}

El Derecho Internacional de los Derechos Humanos y el Derecho Internacional Humanitario, tienen en común que ambos son parte del derecho internacional, es decir que tienen principios y características propias dentro de un sistema integrado de normas, lo que implica que a pesar de sus particularidades, dentro de cada subsistema las normas son creadas por los mismos mecanismos o fuentes tanto convencionales como consuetudinarias, y que desde dos contextos tienen el objeto de proteger a la persona humana. Asimismo la violación de cualquiera de sus normas hace operativas las reglas del derecho internacional general relativas a la responsabilidad internacional tanto de Estados como de individuos.

El cumplimiento de las normas del Derecho Internacional de los Derechos Humanos y del Derecho Internacional Humanitario por todas las partes en conflicto armado, prevendría en alto grado las desapariciones, y convencida de que los Estados Miembros tienen la obligación de respetar y proteger los derechos humanos, se evitarían las desapariciones forzadas.

Se debe garantizar la aplicación del derecho internacional vigente mediante el derecho nacional, que ha de desarrollarse, si es necesario, para prevenir mejor las desapariciones de personas y apoyar mejor a los familiares de las personas desaparecidas.

\section{BIBLIOGRAFÍA}

Asamblea General de las Naciones Unidas. Misión a Honduras. Informe del Grupo de Trabajo sobre Desapariciones Forzadas o Involuntarias. 31 de enero a 2 de febrero de 2007.

Asamblea General de las Naciones Unidas. Resolución A/RES/59/189 "Las personas desaparecidas". 20 diciembre de 2004.

CODEH. Declaración Universal de los Derechos Humanos. Edición Especial (París 1948). Tegucigalpa. 1992. p 20.

Comisión de Derechos Humanos de las Naciones Unidas. Resolución 2005/66 "Derecho a la Verdad". 20 de abril de 2005.

Comisión de Derechos Humanos de las Naciones Unidas. Resolución 2005/26 "Los 
derechos humanos y la ciencia forense". 19 de abril de 2005.

Comité Internacional de la Cruz Roja. Informe del CICR: Capitulo V: Las personas

desaparecidas y sus familiares. Resumen de las conclusiones de consultas

anteriores a la Conferencia Internacional de expertos gubernamentales y no

gubernamentales. 19 al 21 de febrero de 2003.

Constitución de la República de Honduras. 5ta. Ed. Tegucigalpa: OIM.; 2004. 165 p. Honduras. Poder Legislativo. Pacto Internacional de Derechos Civiles y Políticos.

Decreto Núm. 64- 95. La Gaceta Diario Oficial de la República de Honduras. (28293). 24 de Junio de 1997.

Honduras. Poder Legislativo. Pacto Internacional de Derechos Económicos,

Sociales y Culturales. Decreto Núm. 961. La Gaceta Diario Oficial de la

República de Honduras. (23167). 30 de Julio de 1980.

Organización de las Naciones Unidas. Carta de las Naciones Unidas. San

Francisco, Estados Unidos: 1945.

Organización de Estados Americanos. Asamblea General. Convención

Interamericana sobre Desaparición Forzada de Personas. Belém do Pará,

Brasil. 1994.

Protocolo adicional a los Convenios de Ginebra del 12 de agosto de 1949 relativo a

la protección de las víctimas de los conflictos armados internacionales.

(Protocolo I). Ginebra. 8 de junio de 1977.

\section{Documentos electrónicos:}

Aplicación de la Resolución 60/251 de la Asamblea General, de 15 de Marzo 2006.

"Consejo de Derechos Humanos" Informe del Grupo de Trabajo sobre

Desapariciones Forzadas o Involuntarias. Accesible en:

http://www.acnur.org/biblioteca/pdf/5012.pdf Consultado el 14 febrero 2010.

Aplicación del Derecho Internacional Humanitario en América: Informes por país.

Accesible en: http://www.icrc.org/Web/spa/sitespa0.nsf/htmlall/5TDPHE

Consultado el 9 de febrero 2010.

Conflictos armados. Accesible en: http://www.amnesty.org/es/armed-conflict Consultado el 9 de febrero 2010.

Derecho Internacional Humanitario y Guerra Irregular.- CICR. Accesible en: http://www.icrc.org/Web/spa/sitespa0.nsf/htmlall/5TDNW7?OpenDocu ment\&View=defaultBody\&style=custo_print. Consultado el 9 de febrero 2010.

Desaparición forzada - Wikipedia, la enciclopedia libre. Accesible en: http://es.wikipedia.org/wiki/Desaparici\%C3\%B3n_forzada. Consultado el 14 febrero 2010. 
Desapariciones forzadas: una violación del derecho internacional.

Accesible en: http://www.icrc.org/web/spa/sitespa0.nsf/html/humanrights-council-statement-270606. Consultado el 13 febrero 2010.

Expertos de la ONU investigan desapariciones forzadas en Honduras.

Accesible en: http://www.radiolaprimerisima.com/noticias/9230 Consultado 14 febrero 2010.

Fomentar la observancia del Derecho Internacional Humanitario: directrices.

Accesible en:

http://europa.eu/legislation_summaries/humanitarian_aid//33605_es.htm Consultado el 10 de febrero 2010.

Principios y directrices básicos sobre el derecho de las víctimas de violaciones manifiestas de las normas internacionales de derechos humanos y de violaciones graves del derecho internacional humanitario a interponer recursos y obtener reparaciones. Accesible en:

http://www2.ohchr.org/spanish/law/reparaciones.htm. Consultado el 11 de febrero 2010.

Seminario Internacional sobre desaparición Forzada. Accesible en:

http://www.dos-mundos.org/Folleto Desaparicionfinal.pdf. Consultado el 15 febrero 2010. 